\title{
11
}

\section{Values as Fixed and Fluid: Negotiating the Elasticity of Core Values}

\author{
Stephen Sirris
}

\section{Introduction}

Values connect ideals and actions as they are 'conceptions of the desirable which are not directly observable, but evident in moral discourse and patterns of attitudes forming value orientations with relevance to action' (Van Deth \& Scarbrough, 1995, p. 46). Similarly, Chapter 1 of this book reflects this connection by defining values as individual and collective conceptions of desirable behaviours, objectives and ideals that serve to guide or valuate practice'. The present chapter extends our understanding of the interaction between values and practices by utilising a critical perspective on how values are externalised in the work of organisations and managers. Organisations have multiple values that provide guidelines to potentially different courses of action. Such plurality is reflected in studies that categorise values into clusters such as professional, personal or organisational (Cameron, Quinn, DeGraff, \& Thakor, 2014). These sets

S. Sirris $(\varangle)$

VID Specialized University, Oslo, Norway

e-mail: stephen.sirris@vid.no 
of values are safeguarded by various actors. The relation between value sets may range from conflicting to complementing.

Several scholars have shed light on tensions between organisational values. It is well known that replacing existing core values and introducing new ones is a challenge (Rokeach, 1973). In fact, Gehman, Trevino, and Garud (2013) claim that the act of defining core values has received more attention than the process of implementing them. The process of values replacing one another through institutional change has been described by Cha and Edmondson (2006) and Wæraas (2018). Moreover, the tensions between values are highlighted in the distinction between espoused values and values-in-use (Argyris \& Schon, 1978). Cha and Edmondson (2006) also noted how various interpretations of values may give rise to accusations of hypocrisy, owing to the gap between one's saying and doing. Further, values have also been studied as stemming from the institutional logics that are relevant to organisational members (Cameron et al., 2014).

Instead of studying the dynamics between value sets, this chapter examines how the same core values are pursued in different ways and for different ends. Core values constitute a specific set of values that serve to provide a sense of unity. Internal to organisations, core values are identity markers, signalling stability and consistency across organisational structures. They operate at an aggregate level and may be the result of internal consensus as well as approval from wider constituencies and stakeholders (Wæraas, 2018). However, even if values are shared verbatim across organisations, their interpretation in contexts tends to be unique because these contexts are related to people and the organisational history, practices, culture and structure (Schein, 2010). Importantly, the stable yet contingent nature of core values implies tensions and sets the scene for institutional complexity. However, this paradox can easily be overlooked, also by researchers, since values are primarily used to express identity: the enduring, unique and central characteristics of an organisation (Albert \& Whetten, 1985).

Situating this chapter in the perspective of values work, I examine how managers negotiate core values within a firmly established and thriving organisational value discourse. I present a case study of a sudden interruption that triggers values work. I analyse how the discourse manifests 
in local discussions when actors reconstruct the core values in particular settings. This study of the interplay between discourse and managerial efforts is undertaken in a faith-based hospital, which is a rich setting for values work. The case study reports an acute infection crisis where managers in two departments strategically activate and reinterpret the hospital's core values.

My theoretical interest lies in analysing the mechanisms that affect this type of values work. More particularly, I explore the ambiguous nature of values by examining the tension between values that seem fixed at an organisational discursive level and fluid at an individual managerial level. This study explores how values that are initially articulated to promote unity and consensus are subject to the dynamics of conceptual stretching. I conceptualise this stretching as value elasticity which develops the notion that values are ambiguous. The overall aim of this chapter is not only to improve the understanding of how managers engage in values work when negotiating values but also to propose a renewed conceptualisation of such efforts. The research question guiding this work is how do managers negotiate core values as fixed and fluid? In the following sections, I further clarify key concepts and ground my study. Subsequently, I present the research context and methods, describe the case, discuss the main findings and present my concluding remarks.

\section{Theoretical Perspectives on Core Values as Fixed and Fluid}

Goals and means are constantly negotiated in managerial practices. According to Selznick (1957), managers' primary—and paradoxicaljob is to maintain organisational values while simultaneously adapting to changes. Managers essentially safeguard what organisations tend to consider their basic values. The fixed aspects of values are their central, distinctive and enduring qualities. However, as organisations evolve, they risk deviating from their original goals. This drift can occur in the mission and values because of their abstract or 'fuzzy' nature. Values are not entirely fixed, even though organisations may articulate their core values clearly. Actors engage in a dynamic interplay of values and tend to 
employ new interpretations. The same values can refer to different ideas for different people and encapsulate various meanings, signalling fluidity.

Often, employees turn to managers to provide meaning on ambiguous events. Values are by nature ambiguous - capable of carrying historical ideology and allowing for differing views and motivations to promote their acceptance. According to Eisenberg (1984), ambiguity promotes 'unified diversity' for the organisational members and hence facilitates organisational change. When a value allows for varied classifications, it is deemed ambiguous:

Values are expressed in this form because their equivocal expression allows for multiple interpretations while at the same time promoting a sense of unity. It is therefore not the case that people are moved toward the same views (in any objective verifiable sense) but rather that the ambiguous statement of core values allows them to maintain individual interpretations while at the same time believing that they are in agreement. (Eisenberg, 1984, p. 232)

This citation displays a relativist view of meaning, which is contextual and constructed. Ambiguity implies a lack in both message attributes and receiver interpretation, typically evident in situations where equivocality is absent. Omitting contextual cues allows for multiple interpretations. A strategic use of ambiguity serves to accomplish goals, and inconsistency of goals may increase flexibility. Ambiguity thus balances the organisational needs for both individuality and community, which are essentially paradoxical. Ambiguity is well known in relation to reforms, which call for institutional work, and lends to creativity and agency, in which individuals may exploit a reform to their own interests (Thelen \& Mahoney, 2010).

I argue that although core values are fixed by definition, they are negotiated and altered in ways that reveal their elasticity. Core values are subject to ongoing tensions. Gehman et al. (2013, p. 105) commented on this fluidity in the following words:

Even when the "same" values (such as honesty and transparency) were invoked, those involved drew from disparate personal, organizational, professional, institutional, and societal understandings and experiences 
to interpret and assign meaning. What appeared to be agreement about the importance of specific values on the surface revealed a plurality of understandings at a deeper level, sometimes even leading those involved to reach opposing conclusions about the appropriate practices to pursue.

A value discourse may be contested in terms of practices that are deemed valid manifestations of the core values. Discursive practices encompass the more dynamic or even fluid properties of core values when negotiated and lead to divergent configurations of practices. Whereas rules are direct guidelines in articulated situations, values are indicators for actions and offer room for discretion. For example, when core values are interpreted in health care, they are presumably expanded to include elements of professional values (Sirris \& Byrkjeflot, 2019). When the contents of a given value are substantially altered, actors interpret the value to include other notions or practices than typically assumed to be contained in the core value. Metaphorically, defining the boundaries of a given value involves conceptual stretching by contracting or expanding the contents of the value (Cha $\&$ Edmondson, 2006). I study the dynamic tensions between core values that are fixed and fluid by terming the conceptual stretching as value elasticity. I argue that although core values by definition are fixed, actors negotiate and alter values in ways that show elasticity.

\section{Research Context and Methods}

To study managers negotiating values within a distinctive organisational discourse, I employed a method that allowed access to sayings and doings at a micro-level. This chapter reports parts of a larger ethnographic fieldwork involving a single case study conducted within a hospital, which consisted of interviews, observations and archival material.

\section{Research Setting and the Values Discourse}

Hospitals are well known for institutional pluralism and multiple institutional logics. My case hospital is located in a larger Norwegian city and 
functions as local hospital with some specialisations. It has 1700 employees and three managerial levels and caters to a catchment area of 150,000 residents. This particular context and organisation are value laden due to the history of the organisation and its challenges stemming from being diaconal or faith-based. The hospital has over the last decades actively sought to reformulate its Christian mission and identity through several projects on core values. Values may serve as stepping stones between the sacred and the secular, facilitating dialogue between the diaconal history and traditional Christian imagery on the one hand and the growing demands and expectations of the state to deliver welfare services in an increasingly secularised manner on the other (Askeland, Espedal, \& Sirris, 2019). The resurgent attention towards values among faith-based organisations is characterised by the dual context of religion and a secular society (Aadland \& Skjørshammer, 2012). Both share an interest in ethics, despite growing individualistic and anti-dogmatic spirituality.

My case hospital has a strong and long-standing value discourse that has prompted extensive projects on the role of values within the organisation, involving comprehensive processes, managers and employees. The hospital's chosen core values quality, justice, service and respect manifest in many ways and constitute a value discourse inhabiting the organisation and profoundly permeating it. Table 11.1 lists the central value statements obtained from an analysis of the hospital's documents. This chapter explores how unexpected and acute changes triggered the managers to negotiate these values. The case I will discuss was a sudden outbreak methicillin-resistant Staphylococcus aureus (MRSA) infection in the hospital.

The value discourse was incorporated into practices like seminars for new employees, which introduced the core values and its history. Managers also had a value codex as part of their training programme. Plenary settings were arenas for interpretation of the diaconal tradition and values. The CEO actively shared narratives across the organisation about the hospital's founder and the Good Samaritan. He saw it as his mission to articulate the expectations of employees in order to enhance the core values. Narratives served as models for value practices, displaying good examples for others to live by. Moreover, there were several positions such as deacons and chaplains at the hospital. In every department, 


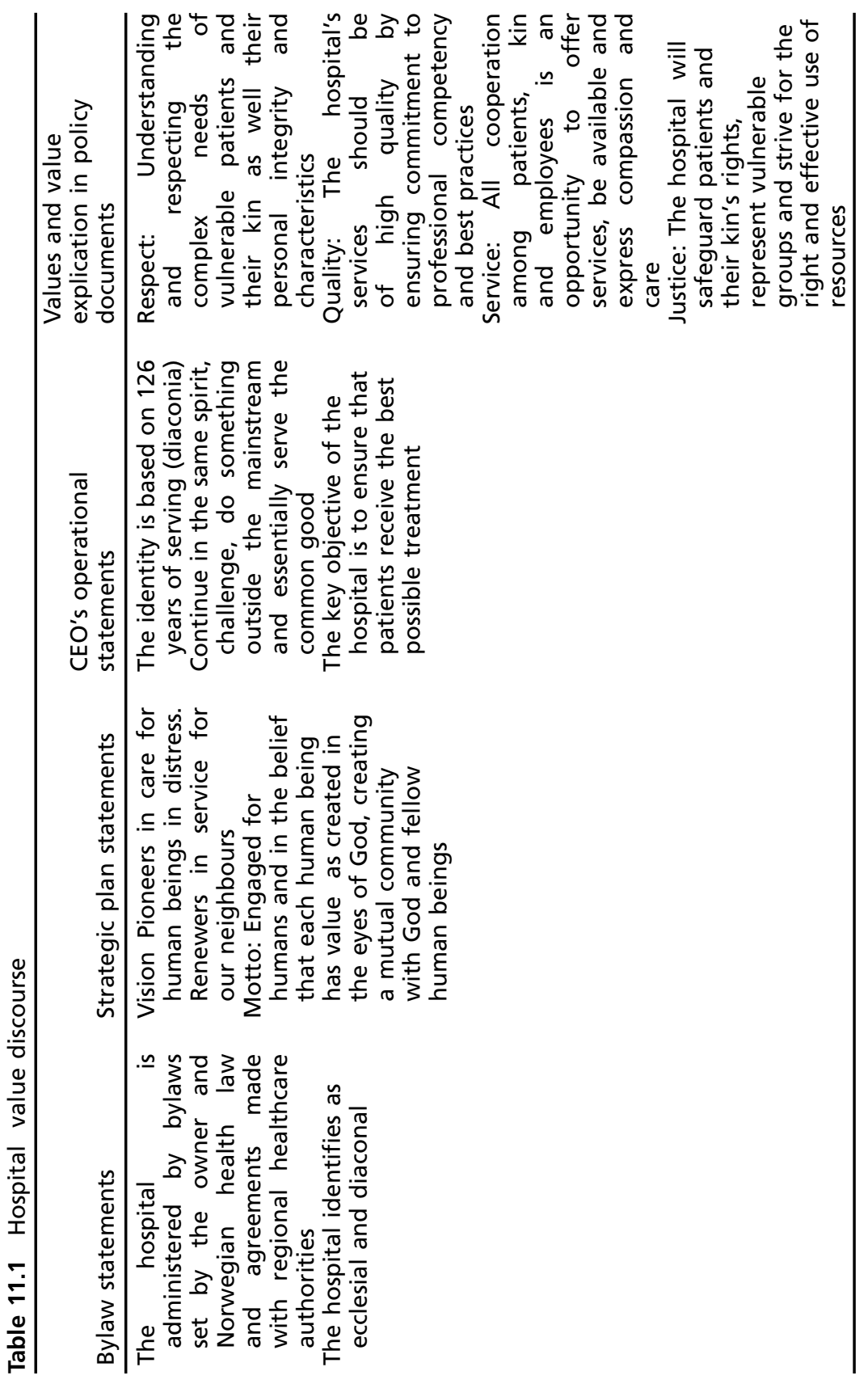


there was a part-time diaconal nurse. Another channel was the provisions of gifts with diaconal spirit as well as books and magazines emphasising the organisation's values and identity.

\section{Data Collection and Analysis}

Data collection for this study was completed between January and June 2016. Data were collected by 10 days of shadowing two nurse middle managers. This process gave access to both actions and interpretations (Denzin \& Lincoln, 2005). By following managers around as they were doing their work, I was able to capture all the activities of the managers for a workweek. Moreover, I interviewed them before and after the shadowing session on managerial roles, co-operation, tasks, challenges and issues they found relevant. Additionally, I interviewed the CEO, two of the managers' superiors and ten subordinates. In total, 15 interviews were performed in Norwegian, recorded and transcribed verbatim. Relevant hospital documents and webpages were analysed. The chapter offers empirical evidence by focusing on how a dramatic situation triggered specific measures that interfered with the daily routines of the units, and how the two managers adopted different strategies for coping with the situation.

Importantly, I chose two hospital units to study how the exact same values were negotiated differently. The first part of my analytical strategy involved thematic coding (Denzin \& Lincoln, 2005). The material related to the infection crisis was easily identified and subjected to open coding. Then, I wrote summaries as narratives of the event from the perspectives of each manager, which are presented below as case descriptions. From this analysis and in-depth descriptions of actions, interactions and intentions, emerging from both the interviews and the observations, I developed categories and themes from the data as exemplary quotes and codes. I analysed the notions that core values encompassed and tabulated the articulation of the values. The key insights from the analysis pertain to how managers align practices with core values. 


\section{Case Description and Findings}

Departing from the notion of values as both fixed and fluid within the hospital's value discourse, I describe the interrupting event that triggered the values work. The data highlight certain mechanisms in the values work, which represent the main themes of the analysis: framing, targeting, negotiating, and a new practice as the outcome.

\section{Framing}

The disruption reported in this case occurred rather suddenly-an outbreak of MRSA infection. During the outbreak, I was engaged in fieldwork within the hospital. When the outbreak was announced, all employees and managers in the surgery and medical departments gathered for an update from the infection control specialists. The event was officially framed as a crisis. It was clearly communicated that the outbreak severely threatened the daily functioning of the hospital. At worst, it would result in a ban on operations and shutdown of complete departments, which meant that no patients could be admitted. However, the specialists' understanding was questioned by some employees. In the plenary session, no specific information was shared about how every hospital department was to operationalise measures to cope with the situation.

The situation was particularly difficult for the surgery unit, where the managerial group met to discuss the next steps. The managers decided on immediate measures with respect to hygiene and strict infection control. They worked out the technicalities that affected the daily operations of the unit, such as washing the ventilation system, possibly closing surgery rooms, building barracks for surgery, prohibiting the wearing of jewellery and wearing new clothes with less particle release. These measures were planned to diminish the danger of contamination. The outbreak threw a department that worked in clockwork fashion into chaos, profoundly changing a system where everything was planned in detail and performed by specialists. 


\section{Targeting}

Following the joint hospital meeting that framed the situation as a crisis, the managerial group of the surgery unit met. The group was headed by the unit manager, Tor, and the assistant unit manager, Anne. This meeting served as a debriefing and was aimed at outlining the next steps and preparing for the staff meeting on the following day.

Tor. I have to consider quality, which means safety for patients. Quality is paramount. Does anyone disagree?

Anne: Whatever we do, care for the patients must be the priority in this crisis. Not inflicting any danger. Perform quality work, as always. Yet, we also have to think about the employees.

The sequence of the conversation highlights the severity of the situation. The interpretation of the situation as a crisis was confirmed. This unit was faced with the challenge of handling the disruption. The managers displayed commitment to the core values and did not question them. Central to the discussion was identifying the target of the values: patients or clients. This was the starting point for deciding the measures to be taken. The unit manager believed that the patients were the target and that the employees should adjust. This, in turn, led to some confronting.

\section{Confronting}

The discussion gave rise to some tensions between the managerial group and the professionals. In the following session of the meeting, specific measures were discussed like change of clothes, closing of doors and ensuring less traffic. Some measures were prescribed as vital, while others were optional and a matter of discretion, depending on the framing of the situation. It was evident that the core values were evoked to strengthen the argument for strict measures. Quality and respect for patients trumped other concerns. In the discussions following the outbreak, the issue of new clothes-switching from ordinary green cotton clothing to blue surgical paper clothes-was of particular interest. Blue 
clothes were more hygienic but warm and uncomfortable to wear. This indicates a new practice. In their discussion, managers shared some more relevant information: air quality measurements in the surgery rooms had revealed high particulate matter, so measures had to be taken to improve patient safety. Blue clothing was tighter and would reduce the transmission of particles but was highly unpopular among the nurses. The managers decided on a strategy to approach the professionals, since they suspected that this measure would not be appreciated.

The following transcript highlights the conflicts between the management and the employees of the unit. The staff representative was called Hans. Both Tor and Anne wore blue paper clothing. When I made a note of this, Tor replied, 'I do not have to participate in surgery today. A bit symbolic... I want to statue a good example'. In the staff meeting, a nurse asked whether it was acceptable to wear trousers under the blue surgical clothing. The group then discussed different clothing issues.

Tor: We have a crystal clear recommendation, and we must follow it. Clothing is of immediate importance. We must prioritise quality and safety.

Hans: The surgeons, however, sit with open coats. Some anaesthetics even wear jewellery. It is very unhygienic with maintenance work in the corridors.

Tor: We are the ones who must take the lead and set a good example.

Hans: Heat makes the blue surgical clothing melt. It burns easily.

Tor: We must prioritise fire safety. I too am extremely exhausted by the maintenance work.

Hans: What about the nurses who are allergic to the blue clothing?

Tor: No other hospitals have reported any kind of allergic reactions. Now, we are in crisis. We must use blue clothing.

Hans: Two of the nurses were dripping wet because of the blue clothing. This is not justice or respect!

Tor. There is nothing to discuss! This is how we have to do it now!

This discussion between the manager and the staff representative is an example of the use of values as motivation for actions. Tor emphasised quality, arguing for safety and hygiene for the sake of the patients, while Hans defended the rights of the employees. Hans based his argument on the employees' work conditions and challenged the process of how the 
decisions were made. Further, he noted that while surgery nurses had to strictly follow the rules, the surgeons and anaesthetics seem to flout them. Finally, he addressed the issue of respect: he noted that the staff did not feel that the manager had approached the situation in a respectful or understanding manner. The above excerpt shows that Tor considered the patients the target of core values, which in turn meant confronting the professionals.

\section{Identifying}

Hanne was the unit manager in the medical unit. She met with her assistant, Atle, and a physician. Below is an excerpt of their conversation:

Hanne: I have to protect my staff from this interference. If nurses have to use a disinfecting spray and wash the rooms, there will be no time left for patient care and professional tasks. This is by definition not their job.

Atle: Yes, this means a drop in quality. Such measures prevent us from providing good care. The central hospital management is not very respectful. They don't understand our unit's situation and how the infection affects our work.

Physician: The measures imposed on us are quite out of proportion.

These data challenge the framing of the event as a crisis. This may partly be explained by the nature of the medical unit in which patients were kept for supervision before and after surgery. In their conversation, the core value of justice was evoked by ridiculing the strict demands for washing the walls and floors but not the door. Hanne's strategy was explicitly to protect the professionals. Instead of confronting them, she emphasised on identification with them.

Her position was also evident in the subsequent staff meeting. Hanne wanted to safeguard her staff from 'this interruption of [their] daily business'. In meetings with the infection control team and physicians, she negotiated strongly, and in staff meetings, she did so by undercommunicating the danger. At the staff meeting, Hanne provided very little information, which signalled that the outbreak was not a crisis. 
Hanne: Have you all seen the e-mail from the infection advisors? These bacteria cannot fly or jump. They are transmitted physically. So, wash your hands and be meticulous about hygiene-as always.

Atle: You also know about the measures. We are told to work based on values. This situation represents challenges for us. I believe that we should be left in peace to realise and work based on the core values, as we see fit.

Employee: We must respect the new guidelines, right?

Hanne: How do we show justice in a situation when we are full with patients? Values keep up reflections. Yet we cannot abdicate from our core work.

\section{Negotiating}

The above sequences reveal strategies for negotiating the fixedness and fluidity of values. These strategies involve both defining the values on a general basis and specifying what practising the value in a new situation means for the actors. In the surgery unit, tensions arose between the two groups of discussion participants: the managerial group and the professionals. Both groups agreed that patient security was of upmost importance, aligning with the core value of quality. The managers argued that the professionals, instead of prioritising the patients, were emphasising their own rights in the name of justice. Both parties agreed that respect was shown to patients but not to employees or managers. The professionals believed that the unit management was loyal towards the hospital management but not towards the employees. In other words, they were disregarding the professional value of collegiality. The target of the core values was thus contested. The managers held differing views about whether the employees or patients were the targets of the core values.

In the medical unit, the two parties were the unit manager and the staff on the one hand and the central management of the hospital, including infection control specialists, on the other. In this unit, the manager identified more clearly with the professionals. She interpreted the infection control measures as an interference to the work of the unit and engaged at length to protect the daily functioning of the unit. Her stance was against that of the hospital management, and she repeatedly 
Table 11.2 Managerial values work

\begin{tabular}{|c|c|c|}
\hline Characteristic & Surgery unit & Medical unit \\
\hline EVENT & \multicolumn{2}{|c|}{ Bacteria outbreak in hospital } \\
\hline FRAMING & $\begin{array}{l}\text { Severe crisis to be } \\
\text { handled }\end{array}$ & $\begin{array}{l}\text { Undue disruption to be } \\
\text { avoided }\end{array}$ \\
\hline TARGETING & Patients & Professionals \\
\hline Confronting & Professionals & Top management \\
\hline Identifying & $\begin{array}{l}\text { Patients and top } \\
\text { managements }\end{array}$ & Professionals \\
\hline \multicolumn{3}{|l|}{ NEGOTIATING } \\
\hline Quality & Safety for patients & $\begin{array}{l}\text { Providing good } \\
\text { professional work }\end{array}$ \\
\hline Justice & Rights of patients & Rights of employees \\
\hline Respect & Enforced measures & $\begin{array}{l}\text { Regular professional } \\
\text { work and routines }\end{array}$ \\
\hline \multicolumn{3}{|l|}{ OUTCOME } \\
\hline $\begin{array}{l}\text { Example of new } \\
\text { practice }\end{array}$ & New clothing & $\begin{array}{l}\text { Strengthen existing } \\
\text { hygienic procedures }\end{array}$ \\
\hline
\end{tabular}

highlighted the violation of the value discourse by the top management. This indicates that core values were tools of loyalty. She frequently confronted her top managers about practices that were not coherent with the core values. She explained that if those values were to be realised, a higher budget was needed. She also asked for the core values to be changed to avoid 'open hypocrisy'. Table 11.2 summarises the main findings and the central efforts of the two managers. The data also indicate a process with overlapping phases of managerial values work.

\section{Discussion}

The research question guiding this study is 'How do managers negotiate core values as fixed and fluid?' Situated within a values discourse of a hospital, the case study illustrates how managers evoke, interpret and reconstruct core values at a time of sudden change. This case is highly relevant to elucidate the phenomenon in question: managerial values work. 


\section{Capturing the Fixed and Fluid Nature of Values}

One of the main contributions of this work is how the data display values as both fixed and fluid. This conceptualisation develops Eisenberg (1984, p. 232) who points out that values promote 'unified diversity' because of their ambiguous nature. Core values appear to be a doubleedged sword: easy to recapitulate but also to alter. Studying the interpretations of core values in situ showcases their dynamics as values, by nature, extend beyond the particular yet are enacted in specific contexts and situations. They are abstract and theoretical yet leave solid impressions and serve as orienting devices for actions (Van Deth \& Scarbrough, 1995). The study findings highlight how values are manifested in an organisation's structure and culture, yet they are also manipulated. Thus, values are simultaneously fixed and fluid.

As expected, both nurse managers demonstrated value consciousness and identified the value discourse as the central driver of their actions in a critical situation. A key difference, however, was the issue of targeting. The middle managers were unsure if they had to be loyal to the top management or the employees, and to the hospital or their own unit. Both managers experienced a mismatch between the core values and the observed practices. They engaged and risked conflicts to avoid this discrepancy between values and practices. This involvement reflects their commitment to the core values as they felt deeply responsible for shaping the practices accordingly. Thus, the observations in this study reveal how the boundaries between values blur.

The phases of framing, targeting, and negotiating show how values are fundamentally imprecise and open to various interpretations in different contexts. On the one hand, a fixed set of core values was recognised in the research context; however, on the other hand, this set was fluid due to its embeddedness in the flux of events. This was evident in the case where the two middle managers channelled information differently. The surgery unit manager was very direct and did not initiate talks; instead, he argued for certain measures. The medical unit manager held back information from her employees and downplayed the heated debates during the managerial meetings. Through their rhetorical efforts—or lack thereof-they 
prioritised the infection event differently. In the surgery unit, the discussions were dramatic, but in the medical unit, the measures were ridiculed and not considered worth fussing over. This indicates that in the medical unit, the core values were not employed to promote the infection control measures. On the contrary, arguing from the perspective quality, the unit was in favour of letting professionals do their work.

\section{The Elasticity of Values}

A second contribution of this work is the conceptualisation of value elasticity. This notion is inspired by the notion of value ambiguity and develops the conceptualisation of the fixed and fluid nature of values. Values are observed to be ambiguous and transfer the responsibility of the 'right' interpretation on to the participating actors (Eisenberg, 1984; Gehman et al., 2013). Not only did I observe the presence of value clarity and unclarity, but I also outlined the process of how actors strategically employ values in their work. The present study provides empirical material and a broader conceptualisation on how elasticity is evident in managerial work. Not only are values open for interpretation, they are subject for negotiating and the interests of actors. This approach to values is more strategic and represents a deliberate way of employing values as tools and means to an end. The focus is thus on achieving something. This points towards the 'hard' aspects of values, suggestive of power and even manipulation.

The benefit of studying a given set of values is that the conceptual dimension of values remains stable. It also reveals conceptual stretching and what actors believe falls within the boundaries of a value definition. A helpful metaphor is the idea of contracting and expanding, suggested by Edmonton and Cha (2006).

The data in this study point to mechanisms that trigger processes with an observable outcome or new practices. Value elasticity refers to the fixed and fluid dynamics of values, in the sense that a value cannot be fully defined. Value elasticity is an inherent characteristic of valuesdetectable when values are negotiated. It surfaces in conceptual stretching, which entails both expanding-widening the held notion of what 
a value covers - and contracting, which is limiting its contents. Unlike rules, values do not come with fixed meanings for any situation, even if the situation is a crisis. The findings of the study serve to correct to the misconception that values act as a unifying force in the midst of a basic disruption. Thus, this study extends the research of Gehman et al. (2013) and reveals new insights about values work in situations of change and crisis. Values have been understood to create unity (Selznick, 1957), but this study shows that this is not always the case. Crises and sudden changes are opportunities for managers to perform strategic values work that is guided by their interests. Rules are not enough; values need to be re-negotiated when the situation demands it.

\section{The Shortcomings of Core Values}

A third contribution of this work concerns the shortcomings of core values on a general level. Core values signal that the organisation is coherent and united because the values guide activities towards shared goals (Wæraas, 2018). Interestingly, all the actors in the case study reiterated the key organisational discourse in the hospital, namely its core values, which appear to hold a sacrosanct position. However, the case study points to the drawbacks of research conducted on fixed sets of values (Cameron et al., 2014) rather than lived values. Even if the 'set-approaches' offer analytical clarity, they may be too static and ideal typical. For example, official statements from the hospital offer value clarity by expressing explicit intentions and standards for actions across situations. These values are the outcome of processes that have been bottom-up, yet they are still values for practice and not necessarily values in practice.

Values and practices are connected, but this work shows that it is naïve to assume consistency between them. The present study questions this assumption by facilitating in-depth insights into a neglected dimension of values through the concept of value elasticity. Whereas fixed core values imply institutionalisation, I explore how their fluid nature emerges in heated discussions. The case shows how interpretations are fluid and are applied to push the interests of the actors. The findings illustrate 
how core values may be undermined and even manipulated. Thus, this chapter provides a critical perspective on values that emphasises their 'darker' side instead of their positive effects (Schein, 2010).

A key objective for this chapter is to investigate if and how core values are part of an ongoing negotiation. I argue that values are not necessarily fixed, even if the core values are well formulated. Rather, actors employ them in dynamic interplay and ongoing interpretations-and the same values may have different meanings for different people. This study has implications for the notions of core values in a theoretical sense, and it provides empirical evidence on how values manifest in managerial practices. This study shows that managers use value elasticity to bring about change. Through the processes of negotiating they explore meanings that lead to new practices. By their efforts, they link organisational continuity with contextual and adaptive change.

The case describes a process from event to outcome containing three parallel micro-processes: framing, targeting and negotiating. On the basis of the contextual findings displayed in Table 11.1, I visualise theoretical contributions in Fig. 11.1. Value elasticity is constituted and evident throughout this process and not only as an outcome.

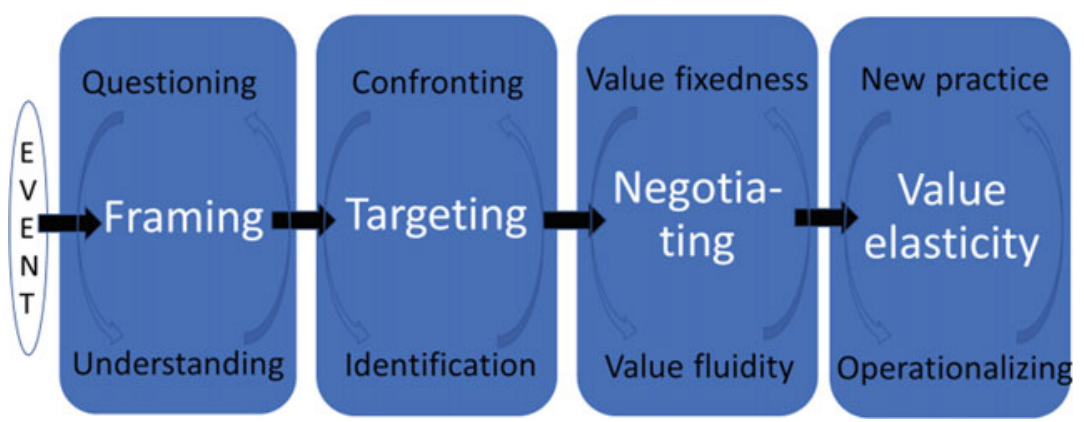

Fig. 11.1 Elasticity in managerial values work 


\section{Concluding Remarks}

This study illustrates how values are devices of orientation that express intentions and guide actions in managerial work. I have empirically demonstrated how core values constitute both unity and diversity. The 'unified diversity' is due to the inherent ambiguity of values. I have developed this notion into a new conceptualisation by proposing values as fixed and fluid; the phenomenon of value elasticity. My findings illustrate how managers perform values work, seeking to align or justify their practices with the core values. In the managerial discussions, some values were evoked and used explicitly to argue for a practice consonant with the managerial strategy. These everyday evocations of the same values are not abstract. Rather, values are used to implicate specific ends and particular actions to be taken.

The chapter shows how values may surface especially in controversies and conflicts. I have provided data on how a value discourse is evoked, presented and represented. Further, I have proposed the construct of value elasticity and a model that visualises it. Values may be identified as priorities, worth, centrality and drivers for actions. In dilemmas, they are evoked and explicated more than in situations where the course of action is clear. The ambiguity provides scope for negotiating values.

Values work is a space of contestation when it comes to the interpretations drawn and the concrete consequences that a given value may imply in a particular case. Core values are open to dialectic claims and ongoing tensions. Discursive practices support this characteristic by showing the elastic properties in processual ways, in which values are negotiated and lead to divergent configurations of practices.

\section{References}

Aadland, E., \& Skjørshammer, M. (2012). From God to good? Faith-based institutions in the secular society. Journal of Management, Spirituality \& Religion, 9(1), 1-19.

Albert, S., \& Whetten, D. A. (1985). Organizational identity. In L. L. Cummings \& B. M. Staw (Eds.), Research in organizational behavior (Vol. 7, pp. 263-295). Greenwich, CT: JAI. 
Argyris, C., \& Schon, D. (1978). Organizational learning: A theory of action approach. Reading, MA: Addison Wesley.

Askeland, H., Espedal, G., \& Sirris, S. (2019). Values as vessels of religion? The role of values in everyday work at faith-based organizations. Diaconia. Journal for the Study of Christian Social Practice, 10(1), 27-49.

Cameron, K. S., Quinn, R. E., DeGraff, J., \& Thakor, A. V. (2014). Competing values leadership. Cheltenham: Edward Elgar Publishing.

Cha, S. E., \& Edmondson, A. C. (2006). When values backfire: Leadership, attribution, and disenchantment in a values-driven organization. The Leadership Quarterly, 17(1), 57-78.

Denzin, N. K., \& Lincoln, Y. S. (2005). The Sage handbook of qualitative research. San Francisco: Sage.

Eisenberg, E. M. (1984). Ambiguity as strategy in organizational communication. Communication Monographs, 51(3), 227-242.

Gehman, J., Trevino, L. K., \& Garud, R. (2013). Values work: A process study of the emergence and performance of organizational values practices. Academy of Management Journal, 56(1), 84-112.

Rokeach, M. (1973). The nature of human values. New York: Free Press.

Schein, E. H. (2010). Organizational culture and leadership (4th ed.). San Francisco: Wiley.

Selznick, P. (1957). Leadership in administration: A sociological interpretation. Evanston, IL: Row Peterson.

Sirris, S., \& Byrkjeflot, H. (2019). Realising calling through managers' identity work. Comparing themes of calling in faith-based and religious organisations. Nordic Journal of Religion and Society, 32(2), 132-147.

Thelen, K. A., \& Mahoney, J. (2010). Explaining institutional change: Ambiguity, agency, and power. Cambridge: Cambridge University Press.

Van Deth, J. W., \& Scarbrough, E. (1995). The concept of values. In J. W. van Deth \& E. Scarbrough (Eds.), The impact of values (pp. 21-47). Oxford: Oxford University Press.

Wæraas, A. (2018). Putting on the velvet glove: The paradox of "soft" core values in "hard" organizations. Administration \& Society, 50(1), 53-77. 
Open Access This chapter is licensed under the terms of the Creative Commons Attribution 4.0 International License (http://creativecommons.org/ licenses/by/4.0/), which permits use, sharing, adaptation, distribution and reproduction in any medium or format, as long as you give appropriate credit to the original author(s) and the source, provide a link to the Creative Commons license and indicate if changes were made.

The images or other third party material in this chapter are included in the chapter's Creative Commons license, unless indicated otherwise in a credit line to the material. If material is not included in the chapter's Creative Commons license and your intended use is not permitted by statutory regulation or exceeds the permitted use, you will need to obtain permission directly from the copyright holder.

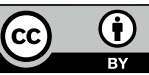

